\title{
Measurement of Net High-affinity Urea Uptake in Maize Plants
}

Laura Zanin*, Nicola Tomasi and Roberto Pinton

Dipartimento di Scienze Agrarie e Ambientali, University of Udine, Udine, Italy

*For correspondence: laura.zanin@uniud.it

[Abstract] Despite its extensive use as a nitrogen fertilizer, the role of urea as a directly accessible nitrogen source for crop plants is still poorly understood. So far, the physiological and molecular aspects of urea acquisition have been investigated only in a few plant species highlighting the importance of a urea transporter in roots, DUR3 (Kojima et al., 2007; Wang et al., 2012; Zanin et al., 2014a). Regarding maize plants, a crop that needs a large amount of urea fertilizer, the capability to take up urea via an inducible and high-affinity transport system has been recently characterized (Zanin et al., 2014a; Zanin et al., 2014b). Here, we described a small-scale protocol suitable for the measurement of urea net high-affinity uptake in roots of intact maize plants.

\section{Materials and Reagents}

1. Maize seeds (Zea mays L., Cv. PR33T56, Pioneer Hi-bred Italia S.p.A., Parma, Italy)

2. Potassium hydroxide $(\mathrm{KOH})$ (Sigma-Aldrich, catalog number: 60370)

3. Calcium sulphate $\left(\mathrm{CaSO}_{4}\right)$ (Sigma-Aldrich, catalog number: 12090)

4. Urea $\left[\mathrm{CO}\left(\mathrm{NH}_{2}\right)_{2}\right]$ (Sigma-Aldrich, catalog number: 15604)

5. Diacetylmonoxime $\left[\mathrm{CH}_{3} \mathrm{C}(=\mathrm{NOH}) \mathrm{COCH}_{3}\right]$ (Sigma-Aldrich, catalog number: 31550)

6. Thiosemicarbazide $\left(\mathrm{NH}_{2} \mathrm{CSNHNH}\right.$ ) (Sigma-Aldrich, catalog number: 89050)

7. Sulphuric acid $\left(\mathrm{H}_{2} \mathrm{SO}_{4}\right)$ (Sigma-Aldrich, catalog number: 320501)

8. Ortho-phosphoric acid $\left(\mathrm{H}_{3} \mathrm{PO}_{4}\right)$ (Sigma-Aldrich, catalog number: W290017)

9. Ferric chloride hexahydrate $\left(\mathrm{FeCl}_{3}\right)$ (Sigma-Aldrich, catalog number: 12319)

10. Sterile deionized water

11. $\mathrm{KCl}$ (Sigma-Aldrich, catalog number: P9541)

12. $\mathrm{CaSO}_{4}$ (Sigma-Aldrich, catalog number: 12090)

13. $\mathrm{MgSO}_{4}$ (Sigma-Aldrich, catalog number: 746452)

14. $\mathrm{KH}_{2} \mathrm{PO}_{4}$ (Sigma-Aldrich, catalog number: $\mathrm{P} 9791$ )

15. NaFe-EDTA (Sigma-Aldrich, catalog number: 03650)

16. $\mathrm{H}_{3} \mathrm{BO}_{3}$ (Sigma-Aldrich, catalog number: $\mathrm{B} 7901$ )

17. $\mathrm{MnSO}_{4}$ (Sigma-Aldrich, catalog number: 221287)

18. $\mathrm{ZnSO}_{4}$ (Sigma-Aldrich, catalog number: Z1001)

19. $\mathrm{CuSO}_{4}$ (Sigma-Aldrich, catalog number: C3036)

20. $\mathrm{Na}_{2} \mathrm{MoO}_{4}$ (Sigma-Aldrich, catalog number: M1651)

21. Nutrient solution (see Recipes) 
22. Urea solution stock (see Recipes)

23. Mixed colour reagent (see Recipes)

24. Mixed acid reagent (see Recipes)

25. Colour development reagent (see Recipes)

\section{Equipment}

1. Growth chamber and hydroponic growing system (including plastic net, plastic pots)

2. pH meter (Jenway, model: 3510)

3. Plastic box $(15 \times 10 \mathrm{~cm} ; \mathrm{H} 4 \mathrm{~cm}$; Figure $1 \mathrm{~A}$, alternatively you can use the bottom of the pipette tips, Sigma-Aldrich, catalog number: P5161)

4. $0.2 \mathrm{ml}$ 96-well plate (AB ANALITICA Advanced Biomedicine, catalog number: B50601; Figure 1B)

5. Clear 96-well microplate with flat bottoms (STARLAB, catalog number: S1837-9600; Figure 1C)

6. Sealing tapes, optically clear (SARSTEDT AG, catalog number: 95.1994)

7. Thermocycler (Eppendorf, model: Mastercycler ${ }^{\circledR}$ personal)

8. Orbital shaker (Janke \& Kunkel IKA-Labortechnik, model: KS 501D)

9. Spectrophotometric multiwell plate reader (TECAN, model: GENios Microplate Reader)

10. Timer

11. Pipettes (Eppendorf, model: 0.5-10 $\mu \mathrm{l}, 20-200 \mu \mathrm{l}, 100-1,000 \mu \mathrm{l}$, Eppendorf Reference ${ }^{\circledR}$ 2) and tips

12. $1.5 \mathrm{ml}$ plastic tubes (Eppendorf, catalog number: 0030 125.150)

13. Absorbent paper (Sigma-Aldrich, catalog number: Z270849)
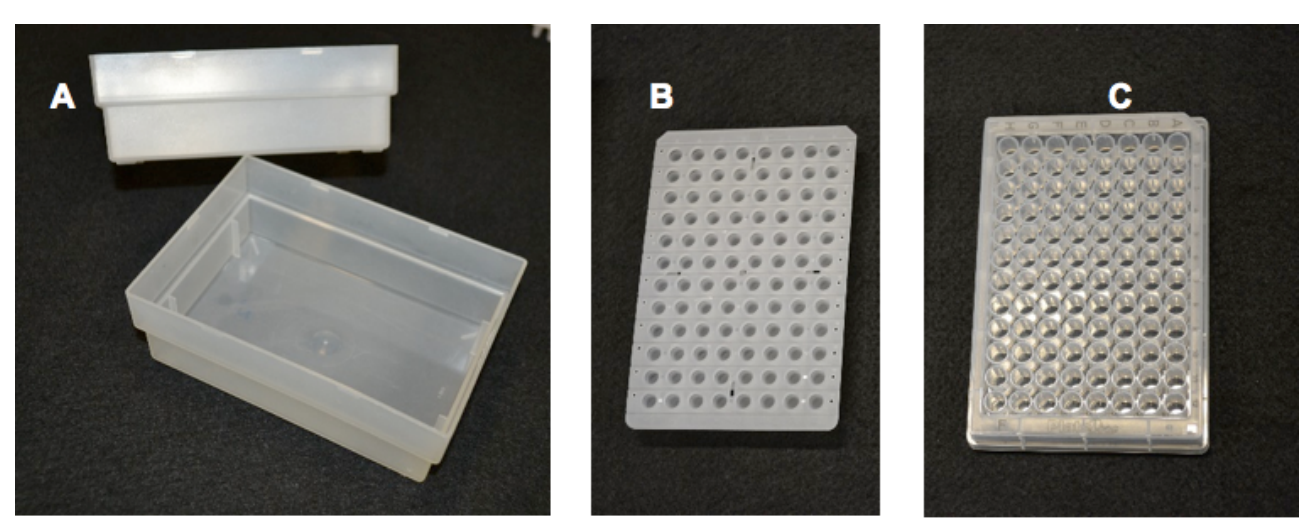

Figure 1. Plastic equipment. A. plastic box; B. $0.2 \mathrm{ml}$ 96-well plate; C. Clear 96-well microplate. 
Procedure

\section{A. Maize growth conditions}

1. Germinate maize seeds on a plastic net placed at the surface of an aerated $0.5 \mathrm{mM}$ $\mathrm{CaSO}_{4}$ solution in a growth chamber at $25^{\circ} \mathrm{C}$ in the dark.

2. After 3 days, transfer the seedlings into an aerated hydroponic system containing 0.5 $\mathrm{mM} \mathrm{CaSO}_{4}$ under controlled climatic conditions: day/night photoperiod, 16/8 h; light intensity, $220 \mu \mathrm{mol} \mathrm{m} \mathrm{s}^{-2} \mathrm{~s}^{-1}$; temperature (day/night) $25 / 20{ }^{\circ} \mathrm{C}$; relative humidity 70 to $80 \%$.

3. After 2 days (5-day-old) plants were transferred for 4 hours in a $\mathrm{N}$-free nutrient solution containing $(\mu \mathrm{M}): \mathrm{KCl} 5 ; \mathrm{CaSO}_{4} 500 ; \mathrm{MgSO}_{4} 100 ; \mathrm{KH}_{2} \mathrm{PO}_{4}$ 175; NaFe-EDTA 20; $\mathrm{H}_{3} \mathrm{BO}_{3}$ 2.5; $\mathrm{MnSO}_{4} 0.2 ; \mathrm{ZnSO}_{4} 0.2 ; \mathrm{CuSO}_{4} 0.05 ; \mathrm{Na}_{2} \mathrm{MoO}_{4}$ 0.05. $\mathrm{N}$ is supplied in form of $1 \mathrm{mM}$ $\mathrm{CO}\left(\mathrm{NH}_{2}\right)_{2}$ (urea-treated plants); or as control, plants are exposed to a $\mathrm{N}$-free nutrient solution (control-plants). The $\mathrm{pH}$ of solution is adjusted to $\mathrm{pH} 6.0$ with potassium hydroxide $(\mathrm{KOH})$.

B. Root uptake of urea and collection of samples

1. Gently remove intact plants (six urea-treated plants and six control plants) from hydroponic system and rinse plant roots for $10 \mathrm{sec}$ in $500 \mathrm{ml}$ of calcium sulphate solution (500 $\mu \mathrm{M} \mathrm{CaSO}_{4}$ ), repeat this step twice (Figure $2 \mathrm{~A}$ ).

2. On an absorbent paper, absorb the excess of calcium sulphate solution from maize plants taking care to not damage roots (Figure 2B).

3. For each measurement, fill three plastic boxes with $40 \mathrm{ml}$ of urea solution ( $8 \mathrm{ml}$ of 1 $\mathrm{mM}$ urea solution stock and $32 \mathrm{ml}$ of $500 \mu \mathrm{M}$ calcium sulphate, final urea concentration $200 \mu \mathrm{M}$ ) and place the boxes on the orbital shaker (speed $90 \mathrm{rpm}$ ).

4. Set the timer to count up $10 \mathrm{~min}$.

5. In each plastic box, place two intact plants submerging the roots in the urea solution (avoid to submerge the seed of the plants). Starting the timer ( $T=0 \mathrm{~min}$ ), collect $60 \mu \mathrm{l}$ of the urea solution in a 96-well plate (Figure $2 \mathrm{C}$-E).

6. Net uptake is measured as urea depletion from the solution per unit of time, removing samples of solution $(60 \mu \mathrm{l})$ for urea determination every 2 min for 10 min, span time during which uptake had a linear trend. Thus, continue to collect the urea solution from each plastic box every two minutes from the start point, at $\mathrm{T}=2,4,6,8$ and $10 \mathrm{~min}$.

7. At the end of the harvesting time, turn off the orbital shaker. In each plastic box, cut and dry roots on absorbent paper; then weigh the maize roots of two plants (Figure $2 \mathrm{~F})$. 


\section{biö-protocol}
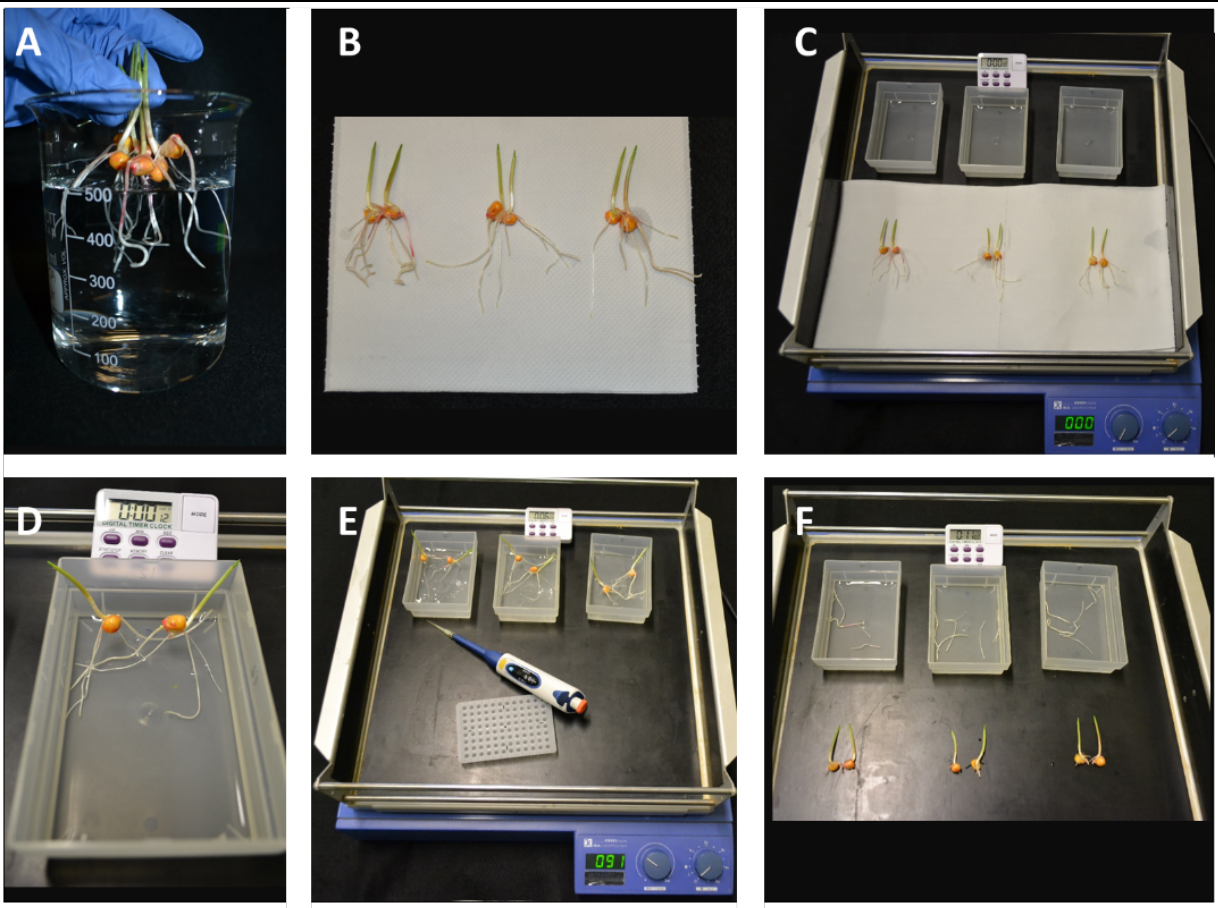

Figure 2. Procedures to collect the samples. A. Rinse the maize roots; $B$. dry maize roots on absorbent paper; C. Prepare plants on an orbital shaker; D. Two plants of maize are transferred in each plastic box, with roots submerged in the urea solution; E. during the experimental time span of $10 \mathrm{~min}$, collect $60 \mu \mathrm{l}$ of urea solution every two minutes; F. at the end of the experiment, cut and weight the roots.

C. Urea standards

1. In $1.5 \mathrm{ml}$ plastic tubes, dilute $1 \mathrm{mM}$ urea solution stock as indicated in Table 1 to create the standard curve.

Table 1. Urea standards

\begin{tabular}{|c|c|c|}
\hline $\begin{array}{c}\text { Urea solution stock } \\
(\mathbf{1} \mathbf{~} \mathbf{M})\end{array}$ & $\begin{array}{c}\text { Calcium sulphate } \\
\mathbf{( 5 0 0} \boldsymbol{\mu M})\end{array}$ & $\begin{array}{c}\text { Final urea } \\
\text { concentration }\end{array}$ \\
\hline $0 \mu \mathrm{l}$ & $1000 \mu \mathrm{l}$ & $0 \mu \mathrm{M}$ \\
\hline $100 \mu \mathrm{l}$ & $900 \mu \mathrm{l}$ & $100 \mu \mathrm{M}$ \\
\hline $120 \mu \mathrm{l}$ & $880 \mu \mathrm{l}$ & $120 \mu \mathrm{M}$ \\
\hline $140 \mu \mathrm{l}$ & $860 \mu \mathrm{l}$ & $140 \mu \mathrm{M}$ \\
\hline $160 \mu \mathrm{l}$ & $840 \mu \mathrm{l}$ & $160 \mu \mathrm{M}$ \\
\hline $180 \mu \mathrm{l}$ & $820 \mu \mathrm{l}$ & $180 \mu \mathrm{M}$ \\
\hline $200 \mu \mathrm{l}$ & $800 \mu \mathrm{l}$ & $200 \mu \mathrm{M}$ \\
\hline $250 \mu \mathrm{l}$ & $750 \mu \mathrm{l}$ & $250 \mu \mathrm{M}$ \\
\hline
\end{tabular}

2. Transfer $60 \mu \mathrm{l}$ of the standards into separate wells of the 96 -well plate. 
D. Urea determination by assay colorimetric reaction

1. Prepare fresh the colour development reagent by mixing $25 \mathrm{ml}$ of mixed acid reagent with $25 \mathrm{ml}$ of mixed colour reagent.

2. Add $120 \mu \mathrm{l}$ of colour development reagent to each well of 96 -well plate containing the samples or the standards.

3. Seal the plate with a sealing tape.

4. Incubate for $15 \mathrm{~min}$ at $99^{\circ} \mathrm{C}$ (lid temperature: $105^{\circ} \mathrm{C}$ ) in a thermocycler.

5. Cool the samples for $5 \mathrm{~min}$ on ice.

6. Remove the sealing tape from the plate and transfer $160 \mu \mathrm{l}$ of all samples in a clear 96-well microplate with flat bottoms.

Note: To avoid to loss material, de-pressurize the wells with a needle before removing the sealing tape from the plate.

7. Measure the absorbance at $540 \mathrm{~nm}$ using a microtiter plate reader (Figure 3).

\begin{tabular}{|c|c|c|c|c|c|c|c|c|c|c|c|c|}
\hline$<>$ & 1 & 2 & 3 & 4 & 5 & 6 & & & & & & 12 \\
\hline A & 0.003206 & 0.006772 & 0 & 0.4215 & 0.4136 & 0.4046 & 0 & 0 & 0 & 0 & 0 & 0 \\
\hline B & 0.215772 & 0.184206 & 0 & 0.4090 & 0.4043 & 0.3935 & 0 & 0 & 0 & 0 & 0 & 0 \\
\hline C & 0.254739 & 0.260739 & 0 & 0.3975 & 0.3982 & 0.3864 & 0 & 0 & 0 & 0 & 0 & 0 \\
\hline D & 0.297472 & 0.304639 & 0 & 0.3909 & 0.3872 & 0.3749 & 0 & 0 & 0 & 0 & 0 & 0 \\
\hline E & 0.338606 & 0.348764 & 0 & 0.3816 & 0.3772 & 0.3621 & 0 & 0 & 0 & 0 & 0 & 0 \\
\hline$F$ & 0.370806 & 0.384372 & 0 & 0.3701 & 0.3714 & 0.3581 & 0 & 0 & 0 & 0 & 0 & 0 \\
\hline G & 0.414306 & 0.427772 & 0 & 0 & 0 & 0 & 0 & 0 & 0 & 0 & 0 & 0 \\
\hline $\mathrm{H}$ & 0.509072 & 0.558506 & 0 & 0 & 0 & 0 & 0 & 0 & 0 & 0 & 0 & 0 \\
\hline
\end{tabular}

Figure 3. An example of output data from a microtiter plate reader at $540 \mathrm{~nm}$. In blue and red are highlighted standards and samples, respectively.

8. The capacity of maize roots to take up urea was determined measuring urea depletion from the solution during the time span of 10 minutes. Net-uptake rates of urea were expressed as $\mu \mathrm{mol}$ urea/g root fresh weight $(\mathrm{FW}) / \mathrm{h}$. An example of calculation is provided in Supplemental file 1.

\section{Notes}

After the harvesting, it is possible to freeze the samples at $-20^{\circ} \mathrm{C}$ and in the following day proceed the samples.

The urea was determined by diacetylmonoxime and thiosemicarbazide colorimetric assay modified from Killingsbaeck (1975) and Mérigout et al. (2008). In order to analyze a great numbers of samples, the colorimetric reaction was performed using 96-well microplates and the volumes of reagents were optimized. Kojima et al. (2007) used the same colorimetric reaction to determined urea accumulation in Arabidopsis tissues. The authors pointed out that the ureides allantoin, ornithine, arginine, and uric acid, did not interfere with urea determinations, although other ureides were not tested. 


\section{$\underline{\text { Recipes }}$}

1. Nutrient solution

$\mathrm{KCl} 5 \mu \mathrm{M}$

$\mathrm{CaSO}_{4} 500 \mu \mathrm{M}$

$\mathrm{MgSO}_{4} 100 \mu \mathrm{M}$

$\mathrm{KH}_{2} \mathrm{PO}_{4} 175 \mu \mathrm{M}$

$\mathrm{NaFe}$-EDTA $20 \mu \mathrm{M}$

$\mathrm{H}_{3} \mathrm{BO}_{3} 2.5 \mu \mathrm{M}$

$\mathrm{MnSO}_{4} 0.2 \mu \mathrm{M}$

$\mathrm{ZnSO}_{4} 0.2 \mu \mathrm{M}$

$\mathrm{CuSO}_{4} 0.05 \mu \mathrm{M}$

$\mathrm{Na}_{2} \mathrm{MoO}_{4} 0.05 \mu \mathrm{M}$

2. Urea solution stock

$1 \mathrm{mM}$ urea

$500 \mu \mathrm{M}$ calcium sulphate

3. Mixed colour reagent

7\% (v/v) 0.2 M diacetylmonoxime

$7 \%$ (v/v) $0.05 \mathrm{M}$ thiosemicarbazide

4. Mixed acid reagent

$20 \%(\mathrm{v} / \mathrm{v})$ sulphuric acid

9\% (v/v) ortho-phosphoric acid

$0.06 \%(\mathrm{v} / \mathrm{v}) 74 \mathrm{mM}$ ferric chloride hexahydrate

5. Colour development reagent

$50 \%(\mathrm{v} / \mathrm{v})$ mixed colour reagent

$50 \%(\mathrm{v} / \mathrm{v})$ mixed acid reagent

\section{Acknowledgments}

The procedures for the root-uptake measurements were adapted from previous studies on nitrate uptake (Rizzardo et al., 2012). The work was supported by a grant from the Italian autonomous region of Friuli Venezia Giulia and the Italian Ministry of University and Research.

\section{References}

1. Kojima, S., Bohner, A., Gassert, B., Yuan, L. and von Wiren, N. (2007). AtDUR3 represents the major transporter for high-affinity urea transport across the plasma membrane of nitrogen-deficient Arabidopsis roots. Plant J 52(1): 30-40. 
2. Merigout, P., Lelandais, M., Bitton, F., Renou, J. P., Briand, X., Meyer, C. and Daniel-Vedele, F. (2008). Physiological and transcriptomic aspects of urea uptake and assimilation in Arabidopsis plants. Plant Physiol 147(3): 1225-1238.

3. Rizzardo, C., Tomasi, N., Monte, R., Varanini, Z., Nocito, F. F., Cesco, S. and Pinton, R. (2012). Cadmium inhibits the induction of high-affinity nitrate uptake in maize (Zea mays L.) roots. Planta 236(6): 1701-1712.

4. Wang, W. H., Kohler, B., Cao, F. Q., Liu, G. W., Gong, Y. Y., Sheng, S., Song, Q. C., Cheng, X. Y., Garnett, T., Okamoto, M., Qin, R., Mueller-Roeber, B., Tester, M. and Liu, L. H. (2012). Rice DUR3 mediates high-affinity urea transport and plays an effective role in improvement of urea acquisition and utilization when expressed in Arabidopsis. New Phytol 193(2): 432-444.

5. Zanin, L., Tomasi, N., Wirdnam, C., Meier, S., Komarova, N. Y., Mimmo, T., Cesco, S., Rentsch, D. and Pinton, R. (2014a). Isolation and functional characterization of a high affinity urea transporter from roots of Zea mays. BMC Plant Biol 14: 222.

6. Zanin, L., Zamboni, A., Monte, R., Tomasi, N., Varanini, Z., Cesco, S. and Pinton, R. (2015). Transcriptomic analysis highlights reciprocal interactions of urea and nitrate for nitrogen acquisition by maize roots. Plant Cell Physiol 56(3): 532-548. 